\title{
Publicidad y juegos digitales en el cotidiano de niños españoles y brasileños: un análisis de la recepción infantil ${ }^{1}$
}

\author{
Pâmela Saunders UCHÔA-CRAVEIRO \\ Universidad de Vigo (España) \\ pamela_uchoa@yahoo.com.br \\ José Riverson ARAúJo CYSNE RIOS \\ Universidade Federal do Ceará (Brasil) \\ riverson@ufc.br
}

Recibido: 09/10/2012

Aceptado: 23/01/2013

\section{Resumen}

La publicidad está presente en el cotidiano de los niños, influenciando en sus juegos y, por tanto, en su manera de entender y descubrir el mundo. Los juegos digitales no son solamente una manera de jugar propia de los niños que nacieron en la era digital, también son espacios lúdicos utilizados por las marcas para ofrecer placer, valores y realización personal en forma de mensajes publicitarias. Este trabajo objetiva entender como los niños reciben el contenido comercial de los juegos en internet a través de un análisis de entrevistas realizadas con niños brasileños y españoles. El análisis de contextos infantiles de países distintos ha posibilitado la comprensión del objeto de estudio en una perspectiva más amplia.

Palabras clave: Infancia, juegos digitales, publicidad, consumo.

\section{Advertising and digital games in the daily life of}

Brazilian and Spanish children: an analysis of the children's reception

\begin{abstract}
Advertising is present in the daily life of everyone, including children, influencing their games and, therefore, their way of understanding and discovering the world. Digital games are not only a way to play typical of children who were born in the digital era, but are also recreational spaces used by the brands to offer pleasure, values and self-fulfillment in the shape of advertising messages. This work aims at studying how children receive the commercial content of the games on the Internet by analyzing some interviews that were carried out with Brazilian and Spanish children. The analysis of children's contexts of different countries has enabled the understanding of the issue in a broader perspective.
\end{abstract}

Keywords: Childhood, digital games, advertising, consumption.

\section{Referencia normalizada}

UCHÔA-CRAVEIRO, Pamela S. y ARAÚJO CYSNE RIOS, José R. (2013): "Publicidad y juegos digitales en el cotidiano de niños españoles y brasileños: un análisis de la recepción infantil". Estudios sobre el Mensaje Periodístico. Vol. 19, Núm. especial marzo, págs.: 501-509. Madrid, Servicio de Publicaciones de la Universidad Complutense.

Sumario: 1. Introducción. 2. Metodología. 3. La infancia y las nuevas tecnologías. 4. Los juegos digitales y la publicidad. 5. Percepción de niños brasileños y españoles sobre la publicidad en los juegos digitales. 6. Conclusiones. 7. Referencias bibliográficas.

1 Este artículo es parte de una investigación en curso para ser defendida como tesis doctoral en la Universidad de Vigo. 


\section{Introducción}

Los juegos infantiles son reflejos de los símbolos, significados, imágenes y valores de una sociedad. Para entender lo que es ser un niño en los días actuales, debemos considerar la influencia de los medios de comunicación de masas y de las nuevas tecnologías en sus juegos, pues es a través de ellos que los niños entienden el mundo.

Este trabajo investiga cómo los niños que nacieron en la era digital utilizan internet como un espacio para jugar. Además, considerando que los juegos infantiles así como diversas facetas de la vida moderna están permeadas por la lógica del consumo, buscamos en el estudio entender cómo los niños reciben y entienden los mensajes publicitarios presentes en las páginas web de juegos.

Para ello, hemos analizado entrevistas con niños españoles y brasileños con el objetivo de observar las diferencias y semejanzas en lo que piensan los niños de ambos países sobre la publicidad en internet.

El estudio ha permitido revelar la fuerte presencia de los juegos digitales en el cotidiano de los niños, medir el interés infantil por la publicidad en los juegos digitales, escuchar la opinión de los niños acerca de los productos ofrecidos por los anuncios mientras juegan en internet, verificar la influencia de publicidad en sus prácticas de consumo, verificar la existencia de una cultura infantil global en que niños de países distintos son conectados por la manera de interactuar en internet.

\section{Metodología}

Este estudio envolvió entrevistas con niños de 9 a 11 años de dos ciudades: Pontevedra (España) y Fortaleza (Brasil). La franja etaria elegida se justifica porque los niños entre 9 y 11 años se encuentran en una etapa en la que incorporan conceptos con más facilidad y tienen el sentido crítico más acentuado que aquellos de edad menor.

Para recopilar los datos necesarios para la investigación, ocurrieran dos reuniones en el aula de ordenadores de una escuela de la ciudad de Pontevedra en los días 14 y 21 de diciembre de 2011 en que participaron 29 niños, y una reunión en una escuela en la ciudad de Fortaleza, donde 20 niños participaron el 21 de mayo de 2012. Niños y niñas de los dos países tomaron parte en la investigación, sin embargo, para facilitar la escrita será usada la palabra niño en el masculino.

Durante las reuniones efectuadas en las escuelas citadas, mientras los niños jugaban en las páginas web de juegos, se hicieron preguntas para entender su relación con los juegos digitales, así como sus percepciones acerca de los anuncios publicitarios presentes en eses juegos. Cada reunión tuvo 1 hora y 30 minutos de duración.

Al trabajar con niños, hemos tratado de establecer un diálogo caracterizado por la espontaneidad para que los encuestados tuvieran libertad de expresarse y para que fueran revelados aspectos subjetivos de sus respuestas al tema investigado. Por ello, no se utilizaron cuestiones de múltiple escoja, las cuales podrían perjudicar la espontaneidad de las respuestas. Por tanto, se utilizó la técnica de entrevista semi-estructurada que, según Triviños (1987), se caracteriza por preguntas básicas respaldadas por teorías e hipótesis relacionadas con el tema investigado. En la entrevista semi-estructurada, es utilizado un guión con preguntas claves que se completa con otras cuestiones que se consideran importantes por el investigador durante la entrevista. 
La entrevista permitió recoger las informaciones necesarias para la comprensión de algunos aspectos de la investigación, entre ellos, las razones para el interés de los niños por los juegos digitales y cómo perciben el contenido comercial presente en ellos. ¿Cuál es, por ejemplo, su opinión con respecto a los anuncios que aparecen en los juegos? ¿Les gustan, les molestan, no les importan? ¿Son influenciados por este tipo de publicidad? ¿Suelen desear consumir los productos ofrecidos en los anuncios mientras juegan?

Las declaraciones de los niños brasileños y españoles no han sido consideradas como simples opiniones, sino como formas de comunicación y representación de la realidad de sus países.

\section{Nuevas tecnologías e infancia}

La infancia es un artefacto social y histórico que sufre influencias de las transformaciones sociales, históricas, culturales, políticas y económicas que ocurren en la sociedad (Steinberg y Kincheloe, 2004). Por tanto, podemos decir que el surgimiento de los medios de comunicación de masas y el desarrollo de las nuevas tecnologías han contribuido para moldear la concepción actual de la infancia.

La generación de niños que nació en el contexto de las tecnologías de comunicación y información es definida por Palfrey y Gasser (2011) como nativos digitales, es decir, las jóvenes élites de cualquier sociedad que nacieron en la era digital y son unidas por la forma en que se relacionan con la información, las nuevas tecnologías y con las otras personas.

A través de sus relaciones con las tecnologías, los niños están construyendo y reconstruyendo la cibercultura infantil que, según Capparelli (2002), es una cultura que se define a partir de la transmisión y del intercambio en la red de actitudes, comportamientos, creencias, conocimientos y formas sociales. En el ciberespacio los niños participan activamente de la sociedad, creando e interviniendo en el proceso de cultura.

Para Tapscoot (1999), la internet se ha convertido en la principal herramienta de esa generación en la cual se constituye la infancia digital. La facilidad con que utilizan las nuevas tecnologías como internet es una evidencia de la transformación en el cotidiano de los niños cuando, por ejemplo, se apropian de los juegos digitales para obtener experiencias lúdicas.

Los juegos en internet han ganado espacio en las formas de entretenimiento de los nativos digitales. En las entrevistas realizadas con los niños españoles y brasileños participantes de este estudio, ha sido posible observar cómo la red ha promovido una reestructuración en los juegos infantiles al proporcionar a los menores nuevas maneras de construir y participar de la cultura lúdica infantil.

Los niños entrevistados de España y Brasil afirmaron que utilizan internet frecuentemente para jugar. Algunos han dicho que juegan al menos una vez por semana, otros tres veces o sólo en los fines de semana y algunos han afirmado que se divierten todos los días con los juegos digitales.

Aunque los entrevistados demostraron la fuerte influencia de la tecnología digital en su tiempo libre, también reveló que los juegos tradicionales continúan vivos en su 
cotidiano lúdico. Cuando indagados sobre cuáles juegos les gustan, además de los digitales, citaron muchos juegos tradicionales.

Los niños españoles mencionaron 22 juegos diferentes de los cuales 5 están relacionados con la práctica de deportes (baloncesto, fútbol, golf, tenis, triatlón) y 12 pueden ser considerados tradicionales (cuerda, cocinar, dibujar, escondite, hacer trabajos manuales, juegos de mesa, jugar con los hermanos, jugar en la plaza, muñeca, pillapilla, pintar). Además, ver televisión e ir al cine fueron citados como tipos de juegos, lo que muestra que los niños consideran juegos todo lo que hacen en su tiempo libro para divertirse. Tres juegos han se destacado por el número de veces que han sido mencionados, son ellos: fútbol, videojuegos y juegos de mesa.

Los niños brasileños citaron 18 juegos diferentes de los cuales 5 está relacionados con prácticas deportivas (fútbol, baloncesto, voleibol, bicicleta, patines) y 7 tradicionales (muñeca, jugar de casita, juego de mesa, escondite, pilla-pilla, bola, cocinar). También mencionaron: videojuegos, ver televisión, ir al cine, leer libros, jugar de lucha y jugar en la piscina. Así como los niños españoles, los dos juegos más mencionados por los brasileños fueron: fútbol y videojuegos. El tercer más citado fue jugar de muñeca.

Luego, podemos concluir que las formas lúdicas tradicionales no fueron necesariamente abandonadas por los nativos digitales. Es verdad que los juegos virtuales hacen parte de la realidad de los niños que tienen la oportunidad de jugar en internet, sin embargo, no deben ser vistos como la única manera de jugar actualmente, pues el acto de jugar en la red no limita la cultura lúdica infantil. Al contrario, como muestra el análisis de lo que dijeron los entrevistados españoles y brasileños, los niños experimentan y crean nuevas posibilidades de jugar.

Una vez que los juegos infantiles son determinados por los valores, ideologías y cultura de cada país, el estudio también evidenció cómo es la cultura del jugar en internet en España y en Brasil. Fue posible observar que, a pesar de la distancia geográfica, los niños españoles y brasileños están conectados por la manera de interaccionar a través de internet. Hubo más semejanzas de lo que diferencias en las respuestas acerca de cómo juegan en la red. Los niños de países juegan frecuentemente en internet, sin embargo continúan se divirtiendo con juegos tradicionales.

Reflejar sobre la influencia de internet en la cultura lúdica infantil es una manera de entender los nativos digitales. Sin embargo, para ello, es necesario considerar que la internet, además de ser un nuevo espacio en que los niños tienen la oportunidad de experimentar nuevas emociones cuando juegan, es al mismo tiempo un lugar de transmisión de contenido comercial de marcas y empresas. Pues como afirma Rifkin (apud Capparelli, 2002, p. 139), la expropiación de diversas facetas de la vida en relaciones comerciales es una característica importante del capitalismo moderno.

Los niños no son vistos por las empresas solamente como simples usuarios de los juegos digitales, pero sobretodo son considerados consumidores en el ambiente virtual. Por consiguiente, son las marcas que patrocinan la construcción de la cultura lúdica infantil en internet, presentando contenidos comerciales en los juegos digitales con el objetivo de generar una relación con los niños haciendo de ellos consumidores potenciales. 
La próxima sección hace una breve reflexión sobre cómo la publicidad se aprovecha de las páginas web de juegos para ofrecer los más variados productos a los niños.

\section{Los juegos digitales y la publicidad}

Como comentado, los nativos digitales poseen características y modos de vida muy distintos de las generaciones anteriores. Están en sintonía con lo que está sucediendo a su alrededor, incluso en el mundo del consumo. Muchas veces, saben antes de sus padres lo que ocurre en el mundo de la moda, por ejemplo, o lo que surge de nuevo en el mercado. Las marcas han constatado esos cambios en el comportamiento de los niños y realizan acciones direccionadas a los jóvenes consumidores (SAUNDERS, 2011). Según Kincheloe y Steinberg (2001), lo que ocurre es una producción corporativa de la infancia en que los intereses comerciales son más valorados que el bien estar, es decir, los niños no son vistos como niños por las marcas sino como nuevos consumidores.

En el mundo digital, los pequeños también son vistos como consumidores. Las autoras Camboim y Patriota (2010) comentan que el aspecto educacional no es el único propulsor de la cibercultura infantil, pues es necesario considerar también el aspecto del consumo que incentiva y patrocina la construcción de esa cultura.

Sampaio (2009) resalta que uno de los aspectos que debemos considerar es el límite impreciso y, muchas veces, inexistente entre el contenido comercial y no comercial en las páginas web destinadas a los niños. Pues innúmeros estudios revelan que niños con menos de 8 años no poseen capacidad de comprender los argumentos persuasivos de la publicidad e incluso de percibir la transición entre el contenido del juego y de un mensaje comercial. Según esos estudios, la capacidad de construir una percepción más crítica sobre los anuncios publicitarios solo acontece a partir de los 12 años.

Los juegos digitales, por ejemplo, son repletos de apelaciones publicitarias. Las páginas web de juegos son espacios eficaces para que las marcas despierten el deseo consumidor en la infancia, una vez que los anuncios publicitarios son presentados a los niños de manera interactiva y lúdica mientras están jugando.

En este estudio, optamos por escuchar lo que piensan algunos niños brasileños y españoles, de 9 a 11 años, a respecto de la publicidad en los juegos digitales. El análisis de entrevistas de niños de países distintos ha posibilitado la comprensión del objeto de estudio en una perspectiva más amplia, además de haber permitido conocer y comparar algunas características de los niños que viven en Brasil y en España.

\section{Percepción de niños brasileños y españoles sobre la publicidad en los juegos di- gitales}

Como dicho anteriormente, fue realizada una entrevista con niños brasileños y españoles sobre sus reacciones frente a la publicidad en los juegos online. El análisis evidenció que hay más semejanzas que diferencias en lo que piensan los niños de esos dos países.

Sobre la atracción por el contenido comercial de las páginas web de juegos, hay una opinión común entre los entrevistados. Todos afirmaron no prestar atención a los anun- 
cios cuando están jugando, unos simplemente desprecian la publicidad y otros se irritan con los anuncios.

Otra razón para que los anuncios molesten a los niños es que ellos interrumpen los juegos. Muchos surgen en la pantalla mientras el usuario juega y no se consigue cerrarlos. Los niños entrevistados reclaman, pues, cuando abren las páginas web de juegos, quieren sólo jugar y son obligados a ver publicidad.

Un dado interesante es que la credibilidad en la publicidad en internet no es demostrada en lo que dicen los entrevistados. En la opinión de niños de Brasil y España, los anuncios no deben tomarse en serio, porque "no dicen la verdad". Especialmente aquellos que divulgan milagrosos productos para bajar de peso y ofrecen premios supuestamente falsos. La falta de credibilidad en los mensajes publicitarios, algunas veces, resulta de la orientación de los responsables por los niños que, objetivando evitar daños morales y financieros por el mal uso de internet, aconsejan sus hijos a no pulsar en los anuncios.

A pesar de las varias opiniones negativas presentadas sobre los anuncios en los sitios de juegos, no se puede decir que los niños son contra la publicidad. Se observó en lo que dijeron muchos de los entrevistados que, en la opinión de ellos, internet no es un medio adecuado para transmitir mensajes publicitarios. Para los niños brasileños y españoles, el lugar de las propagandas es en la televisión, pues, en ese vehículo, los anuncios suelen ser más interesantes, menos impertinentes y no exigen acciones de aquellos que los veen, diferentemente de las propagandas de la web que exigen que los niños pulsen en la pantalla, respondan a preguntas, escriban algo, etc.

Los entrevistados sugirieron cambios para que las propagandas dejaran de ser un incómodo. Las dos proposiciones más comentadas fueron la disposición de los anuncios que deberían estar exclusivamente en la lateral de la pantalla, y el contenido de los mensajes que deberían divulgar productos más relacionados con lo que desean aquellos que juegan en internet. Los entrevistados sugirieron que las empresas realizaran una investigación para saber por lo que ellos se interesan, así, los anuncios serían más atractivos.

La mayoría de los encuestados brasileños y españoles presentaron un discurso rechazando los anuncios publicitarios divulgados en los juegos online, afirmando que no los pulsaban ni prestaban atención en ellos. No obstante, los demandados de los dos países consiguieron mencionar marcas y productos que viran en las propagandas mientras jugaban.

Las marcas y productos mencionados por los hispánicos fueron los siguientes: Audi, Chacon, Coca-Cola, Colacao, Corte Inglés, Decatlón, Ferrari, Movistar, Nike, PlayStation, Telefónica, Umbro y Zara.

Sin embargo, no hubo marcas o productos específicos que predominaron en el discurso de los encuestados españoles. El anuncio del producto iPhone fue el único mencionado por más de un niño y por lo menos más de uno citó propagandas de móviles, coches, ropas y promociones en general.

Las marcas citadas por los niños brasileños fueron: Sky, el juego DDTank, O Boticário, Ana Hickmann y los productos: coches, móviles, tiendas de perfume, películas, productos de pele, tiendas de ropa y juguetes. 
De lo mismo modo que ocurrió con los niños españoles, no hubo ningún producto o marca específica que predominó en la respuestas de los niños brasileños. No obstante, se observó que las marcas y los productos relacionados al mercado de belleza (moda, cosméticos, perfumería) se destacaron en las respuestas de la mayoría.

Cuando indagados si alguna vez desearon consumir un producto visto en un anuncio mientras jugaban, las hablas de los entrevistados españoles se equilibraron. Por un lado hubo aquellos que dijeron no ser influidos por la publicidad, ya que afirmaron nunca haber deseado o comprado algo que vieron en los anuncios en los juegos. Por otro lado, hubo aquellos que afirmaron que ya se interesaron por productos anunciados en sitios de juegos y, incluso, llegaron a comprarlos. iPhone, agua, Coca-cola, botas de fútbol, móviles, juguetes, PSP, Nintendo Wii, juegos para videojuegos fueron productos anunciados en los juegos que fueron deseados y/o comprados por algunos de los niños entrevistados.

La situación es equivalente entre los encuestados brasileños,: hubo aquellos los cuales dijeron que nunca desearon consumir ningún producto visto en anuncios en internet y, en cambio, hubo quien dijo que, además de haber deseado comprar artículos vistos en los anuncios en los juegos online, muchas veces, efectuaron la compra de productos.

A diferencia de los niños españoles, que en su mayoría sólo mencionaron productos y marcas deseadas o compradas, los brasileños describieron con total naturalidad y fluidez situaciones en que cedieron a los elementos persuasivos de la publicidad al consumir algunos de los productos anunciados.

Las respuestas de los niños brasileños también revelaron que ellos no se limitan a sólo desear los productos que se anuncian o a pedir a sus padres que les compren. Los entrevistados de Brasil mostraron familiaridad con las páginas web de compras y describieron situaciones en las que ellos mismos buscaron informaciones sobre productos en internet e incluso compraron en la red.

Por fin, lo que llama la atención en el discurso de los niños de ambas nacionalidades es que muchos de los que antes dijeron que no veían los anuncios mientras jugaban, fueron los mismos que dijeron que ya desearon comprar algo visto en el contenido publicitario de las páginas web. Eso revela que la publicidad de los sitios de juego afectan a los niños que los utilizan para la diversión, incluso aquellos que se sienten molestados por los anuncios y no interactúan con sus mensajes. De algún modo el objetivo de la publicidad se logra, es decir, despierta el deseo de comprar en su público que en ese caso es formado por niños.

\section{Conclusiones}

En este trabajo se buscó hacer una reflexión sobre la influencia de internet en el cotidiano lúdico de niños españoles y brasileños, además de conocer lo que piensan los niños de esos países acerca de la publicidad en las páginas web de juegos. Una vez que este estudio hace parte de una investigación más amplia, los resultados aquí encontrados no son definitivos. Todavía es posible hacer tres consideraciones a partir de lo que ha sido presentado.

Primeramente, se puede decir que, aunque los juegos digitales estén cada vez más presentes en el cotidiano lúdico infantil, los juegos tradicionales continúan divirtiendo 
los niños. Además, es importante mencionar que muchos de los juegos tradicionales citados por los entrevistados son constantemente reproducidos por los juegos digitales. Es posible jugar en las páginas web de hacer comida, vestir muñecas, dibujar o pintar, jugar un partido de fútbol o baloncesto, etc. Por tanto, lo que se ve no es la substitución de los juegos tradicionales por la tecnología digital, sino un diálogo entre los juegos virtuales y reales. Los niños mostraron en ese estudio que continúan sintiendo necesidad de jugar en el espacio físico concreto, aunque expresen que les gusta pasar horas jugando en internet.

Una segunda consideración es que esta investigación ha revelado que los niños de 9 a 11 años poseen sentido crítico acerca de la publicidad en internet, son capaces de evaluar lo que les gustan y lo que les molestan, además de proponer nuevas formas para que las empresas se comuniquen con ellos. De esa forma, es fundamental estimular la capacidad crítica de los niños y esa es una tarea de padres, educadores y gobierno, no olvidando de la responsabilidad ética necesaria a todas las empresas que direccionan su comunicación al público infantil.

Por fin, el estudio ha revelado que los niños brasileños y españoles, a pesar de la distancia geográfica, están conectados por la manera de interaccionar a través de internet. A respecto de la cultura del jugar en internet y de la publicidad presente en los juegos online, los discursos son más semejantes que diferentes, por tanto, podemos decir que el estudio revela un crecimiento de una cultura infantil global.

\section{Referencias bibliográficas}

CAMBOIM, Ana y PATRIOTA, Karla (2010): "A Publicidade para Criança Cibernativa no Contexto da Cibercultura Infantil" em E-compós: http://www.compos.org.br/. [fecha de consulta: 10 de julio de 2011]

CAPPARELLI, Sérgio (2002): "Infância digital e cibercultura", en PRADO, José Luiz Aidar: Crítica das práticas midiáticas: da sociedade de massa às ciberculturas. SãoPaulo, Hacker Editores, pp. 130-146.

KINCHELOE, Joe L; STEINBERG, Shirley R; BRICIO, George E. J. (2004): Cultura infantil: a construção corporativa da infância. Rio de Janeiro, Civilização Brasileira.

PALFREY, John; GASSER, Urs (2011): Nascidos na era digital: entendendo a primeira geração de nativos digitais. Porto Alegre, Artmed.

SAUNDERS UCHÔA CRAVEIRO, Pâmela (2011): $O$ alcance dos valores de consumismo e ideal de beleza no site barbie.com e sua página web em facebook. Trabajo de Fin de Máster en comunicación presentado en la Universidad de Vigo en España.

SAMPAIO, Inês (2009): "Publicidade e infância: uma relação perigosa", en VIVARTA, Veet: Infância e Consumo: estudos no campo da comunicação. Brasília: ANDI, Instituto Alana.

TRIVIÑOS, Augusto N. S (1987): Introdução à pesquisa em ciências sociais: a pesquisa qualitativa em educação. São Paulo, Atlas. 
TAPSCOTT, Dan (1999): Geração Digital: a crescente e irreversivel ascensão da Geração Net. São Paulo, Makron Books.

\section{Pâmela Saunders UCHÔA-CRAVEIRO}

Universidad de Vigo

Doctoranda en Comunicación en la Universidad de Vigo. Realiza investigación sobre la percepción infantil sobre la presencia de la publicidad en los espacios lúdicos de los juegos digitales.

pamela_uchoa@yahoo.com.br

\section{José Riverson ARAÚJO CYSNE RIOS}

Universidade Federal do Ceará, Brasil

Phd in Computacion, University of Ottawa, Canadá, Profesor Asociado de la Universidade Federal do Ceará, Brasil

riverson@ufc.br 